\title{
Evaluation of continuous constant current and continuous pulsed current in sweat induction for cystic fibrosis diagnosis
}

\author{
Carla Cristina Souza Gomez ${ }^{1,2^{*} \dagger}$, Fernando Augusto Lima Marson ${ }^{1,2,3^{*}+} \mathbb{D}$, Maria Fátima Servidoni ${ }^{1,2,4}$, \\ Antônio Fernando Ribeiro 1,2, Maria Ângela Gonçalves Oliveira Ribeiro 1,2, Veruska Acioli Lopes Gama ${ }^{5,6,7}$, \\ Eduardo Tavares Costa ${ }^{5,6}$, José Dirceu Ribeiro ${ }^{1,2}$ and Francisco Ubaldo Vieira Junior ${ }^{5,6,7}$
}

\begin{abstract}
Background: The sweat test (ST) is the gold standard for the diagnosis of cystic fibrosis (CF). However, little is known about sweat induction using different types of currents and waves. In this context, our objective was to develop a device to induce sweat and compare the use of continuous constant current (CCC) and continuous pulsed current (CPC) in individuals with CF and healthy controls.
\end{abstract}

Methods: A prospective cross-sectional study with experimental intervention. The variables of gender, ethnicity, age, and body mass index (BMI) were considered. The method of Gibson and Cooke was used, and the following markers were evaluated: sweat weight, electrical impedance, sufficient sweat amount, and CF diagnosis. Triangular (TPC) or sinusoidal (SPC) pulsed current was applied to the right arm, and CCC was applied to the left arm.

Results: The study analyzed 260 individuals, 141/213 (54.2\%) were female participants, 135/260 (51.9\%) were Caucasians. The distribution of individuals by concentration of chloride at the ST was: (CF) 26/260 (10\%); (borderlines) 109/260 (41.9\%); (healthy) 97/260 (37.3\%); (insufficient weight in sweat) 28/260 (10.8\%). No association was observed between the sufficient sweat amount to perform the ST when we compared the currents. However, the SPC showed a higher amount of sweat weight. Using Bland and Altman plot considering the agreement between the sweat chloride values achieved from $C P C$ [SPC and TPC] and CCC, there was no proportional bias and mean values are unrelated and only explain less than $8 \%$ of the variation. Moreover, TPC presented higher electrical impedance when compared with SPC and CCC. SPC presented lower electrical impedance and higher sweat weight than CCC. Male participants presented lower electrical impedance and higher sweat weight with CCC and TPC, and higher sweat weight with SPC.

Conclusions: The evaluated currents are safe and able to induce and produce sweat in sufficient quantities for the ST. SPC presented lower electrical impedance when compared with other currents. The use of SPC is recommended to induce sweat in patients with sweat problems. Finally, ethnicity, gender, age and BMI did not influence sweat induction at the ST, and no side effect was observed in our study.

Keywords: Continuous constant current, Continuous pulsed current, Sweat test, Sinusoidal pulsed current, Triangular pulsed current

\footnotetext{
*Correspondence: carlacg.gomez@gmail.com;

fernandolimamarson@hotmail.com

${ }^{\dagger}$ Carla Cristina Souza Gomez and Fernando Augusto Lima Marson

contributed equally to this work.

${ }^{1}$ Department of Pediatrics, School of Medical Sciences, University of

Campinas, Cidade Universitária Zeferino Vaz, Barão Geraldo, Campinas, São

Paulo 13083-887, Brazil

Full list of author information is available at the end of the article
}

(c) The Author(s). 2018 Open Access This article is distributed under the terms of the Creative Commons Attribution 4.0 International License (http://creativecommons.org/licenses/by/4.0/), which permits unrestricted use, distribution, and reproduction in any medium, provided you give appropriate credit to the original author(s) and the source, provide a link to the Creative Commons license, and indicate if changes were made. The Creative Commons Public Domain Dedication waiver (http://creativecommons.org/publicdomain/zero/1.0/) applies to the data made available in this article, unless otherwise stated. 


\section{Background}

The evaluation of the cystic fibrosis transmembrane conductance regulator (CFTR) function through the sweat test was a milestone for the diagnosis of cystic fibrosis (CF) (OMIM: \#219700). The sweat test was created around six decades ago by Gibson and Cooke (1959), and so far, it has been considered the main tool for the diagnosis of CF [1]. An early diagnosis due to the sweat test ensured advances in lowering the deterioration of nutritional status and lung function. In addition, the sweat test enabled a better understanding of the disease and the evaluation of the efficacy of new drugs by personalized/ precision medicine [2-5].

The sweat test uses the pilocarpine iontophoresis method to induce sweat and evaluate the amount of chloride in sweat. The diagnosis of CF is confirmed when the levels of chloride in sweat are equal to or greater than $60 \mathrm{mmol} / \mathrm{L}$ considering two sweat tests performed at different moments $[1,2,6-8]$. Although the sweat test is the gold standard for the diagnosis of CF, with numerous published guidelines that recommend it, the literature reports challenges when conducting this test [9-17].

The sweat test involves three stages: induction, collection and measurement of electrolytes. Efficacy is related to the experience of the professional who conducts the test and the use of appropriate equipment to induce sweat. Due to the sweat test complexity, many laboratories worldwide have reported several challenges when conducting it. Then, to standardize the sweat test, the United States of America and Europe were the pioneers in the development of guidelines and reports about the test [7-18]. Brazil does not have its own guideline and several methods are used when conducting the sweat test.

The challenges to conduct the sweat test start in sweat induction. The equipment for sweat induction used in Brazil is mostly manufactured by the CF university centers and does not have authorization from the national health surveillance agency, except for Macroduct (Wescor, Utah, USA), a system that has been used by some centers $[19,20]$.

In the literature, commonly, iontophoresis devices to induce sweat use the constant continuous current of one ampere [21-23]. However, the literature also has reports of efficient delivery of substances through the skin with the use of continuous pulsed current, without risks of burning and discomfort when compared with continuous constant current, a fact that is still controversial in CF $[21,22]$.

This study aimed to develop a low cost sweat induction device and compare the volume of sweat obtained using continuous constant current and continuous pulsed current in individuals with $\mathrm{CF}$ and healthy controls of all age groups and both genders.

\section{Methods}

\section{Individuals enrolled in the study}

We performed a prospective cross-sectional study with experimental intervention, unblinded and nonrandomized, involving individuals with and without CF of all age groups, of both genders, Caucasians or non-Caucasians. Individuals with $\mathrm{CF}$ were recruited from the CF Reference Center of the University of Campinas. Nursery children, adult staff and university students comprised the remaining sample as volunteers.

The individuals with CF were diagnosed through: compatible clinical history, two chlorides quantifications in sweat with values greater than $60 \mathrm{mmol} / \mathrm{L}$, and/or a genetic study of confirmed CFTR gene mutations (OMIM: \# 602421). The volunteers did not have any known chronic disease.

The project was approved by the Research Ethics Committee of the University of Campinas (\#809.090/ 2014). Written informed consent for participation in the study was obtained from participants or, where participants are children, from a parent or guardian.

\section{Devices used to induce sweat}

The sweat-inducing device used in the sweat test was developed by the Instituto Federal de São Paulo and the Biomedical Engineering Center of the University of Campinas. The iontophoresis device used is portable and easy to use, and it offers the possibility to select between continuous pulsed current and continuous constant current, with triangular pulsed current, sinusoidal pulsed current and continuous constant current waveform, at the frequency of $1000 \mathrm{~Hz}$, maximum output current of one $\mathrm{mA}$, and embedded software to support the settings for data control and acquisition, with two brass electrodes of $30 \mathrm{~mm}$ diameter.

The device was developed from a microcontroller and a circuit that generates the continuous constant current and continuous pulsed current signals. The effective root mean square (RMS) value of the current was calculated from the numerical integration of the sampled currents.

During the sweat test, the applied voltage and current values were stored in a memory card every $0.8 \mathrm{~s}$ in 32-slot sampling blocks.

From the voltage and current values recorded in the memory card, curves were reconstructed relative to the waveforms (voltage and current) of each test. With the help of Matlab software, mean electrical impedance was calculated for the total time of the test $(10 \mathrm{~min})$. The stimulation of $10 \mathrm{~min}$ was different from Gibson and Cooke method [1] regarding two main factors: (i) there was evaluated an amperage of one $\mathrm{mA}$ to induce the sweating; (ii) in a previous study, the time of $10 \mathrm{~min}$ presented a greater sweating in the sweat test [23]. 
To ensure the safety and feasibility for the human individuals enrolled in our study, the sweats tests were performed at the tertiary hospital in the presence of a medical doctor in a reference laboratory that performed the sweats tests in our institution during the last 30 years.

\section{Clinical markers evaluated}

The variables of gender (male/female), self-declared ethnicity, age (years), and body mass index were considered. The body mass index was calculated using the following formula: weight $(\mathrm{Kg}) /$ height $^{2}(\mathrm{~m})$, and the $\mathrm{z}$-score analysis for age was included, with data categorized as accentuated slenderness, slenderness, eutrophic, overweight, obesity, and severe obesity. The clinical markers were compared with the results achieved in the sweat tests.

\section{Sweat test}

The method of Gibson and Cooke was performed in the two stages of the sweat test: induction and collection to analysis the concentration of chloride [1].

The distance of two $\mathrm{cm}$ and five $\mathrm{cm}$ between the electrodes were adopted for newborns and the other participants, respectively. To minimize the risk of burning, the gauze was kept completely moist with pilocarpine, and the electrode was attached onto the gauze with an elastic band to prevent electrode displacement on the arm.

For each patient, the mean electrical impedance was calculated for the electrode, gauze and skin assembly during the induction time by the Ohm's law, using the following equation: $\left[\mathrm{Z}=\mathrm{V}_{\mathrm{RMS}} / \mathrm{I}_{\mathrm{RMS}}(\Omega)\right]$. Being: $\mathrm{Z}=$ composite impedance $(\Omega) ; V_{\text {RMS }}=$ effective voltage measured (volts root mean square); $\mathrm{I}_{\mathrm{RMS}}=$ effective current measured (current root mean square). To collect sweat, a $17.5 \mathrm{~cm}^{2}$ filter paper covered with plastic and crepe bandage was used. The concentration of chloride was obtained by manual titration [24], also the analysis was done after an extensively trainee with a technician that performed the sweat test for 30 years using the same protocol. In this context, a gauze was soaked with pilocarpine only to stimulate sweating, and subsequently the sweat collection was performed with filter paper (Whatman ${ }^{\text {Tx }}$ 1001-125, Little Chaltfon, Buckinghamshire, UK) after cleansing the arm.

To minimize the bias, we performed the sweat test using a standard protocol. Also, negative and positive controls were quantified, at the same time, with the sample individuals. The reagents were strictly conditioned and we used: (i) Standard - Sodium chloride $(100 \mathrm{mmol} / \mathrm{L})$; (ii) Nitrate - mercury nitrate $1.1 \mathrm{mmol} / \mathrm{L}$ and $0.9 \mathrm{mmol} / \mathrm{L}$ nitric acid; (ii) Color reagent - Mercury thiocyanate two $\mathrm{mmol} / \mathrm{L}$, ferric nitrate $17 \mathrm{mmol} / \mathrm{L}$ and nitric acid $30 \mathrm{mmol} / \mathrm{L}$. In our sample, we observed a higher variability in sweat test analysis in individuals with the lower concentration of chloride. The manual titration is dependent from the experience of who does the exam, but this technique is suitable to perform the sweat test, and the exam was done in supervision of a technique that performed the test during the last 30 years, as previously declared.

At the sweat test, 10 and 30 min were used for sweat induction and collection, respectively, as well as one $\mathrm{mA}$ current and $1000 \mathrm{~Hz}$ frequency to pulsed current.

With the sweat test, the following data were evaluated: sweat weight $(\mathrm{mg})$, mean electrical impedance, sufficient amount of sweat obtained during induced sweat (weight greater than $75 \mathrm{mg}$ ), and diagnostic parameters of $\mathrm{CF}$ (healthy individuals $=$ chloride $<30 \mathrm{mmol} / \mathrm{L}$; borderline $=$ chloride $\geq 30 \mathrm{mmol} / \mathrm{L}$ to $<60 \mathrm{mmol} / \mathrm{L} ; \mathrm{CF}=$ chloride $\geq 60 \mathrm{mmol} / \mathrm{L}$ ) [8].

\section{Experiment description}

Triangular pulsed current or sinusoidal pulsed current was applied to the left arm of the participants, and continuous constant current to the right arm. The complete details can be visualized at Figs. 1 and 2a.

\section{Statistical analysis}

In the statistical analysis, the sweat weight and electrical impedance of the electrode, gauze and skin assembly obtained with the application of continuous constant current, triangular pulsed current, and sinusoidal pulsed current were compared. In addition, the sweat weight and mean electrical impedance were evaluated in relation to the variables of ethnicity, age, gender and body mass index.

Statistical Package for the Social Sciences, version 23.0 (IBM ${ }^{\circ}$, Armonk, NY, USA), was used in data analysis. The charts were built with MedCalc 13.2.2 (MedCalc Software, Acacialaan 22, B-8400, Ostend, Belgium).

The numerical variables are presented in the study by measures of position and dispersion, and the categorical variables by absolute number and percentage.

In the comparative analysis between the data from the same individual, considering the different tests performed (continuous pulsed current versus continuous constant current), the Wilcoxon signed-rank test of related samples was applied. The Mann-Whitney $U$ test of independent samples was applied to the variables compared between different individuals (triangular pulsed current versus sinusoidal pulsed current and clinical markers for ethnicity, age, gender and body mass index for sweat weight and electrical impedance). Also, we performed the association between the difference of continuous pulsed current and continuous constant current, regarding sweat weight of sinusoidal pulsed current and triangular pulsed current by Mannn-Whitney $U$ test of independent samples. The comparison was conducted for sweat weight (whether or not sufficient for the quantification of the concentration of chloride) and CF diagnosis, in the comparison between right and left arms, using McNemar's tests and the Wilcoxon signed-rank test 


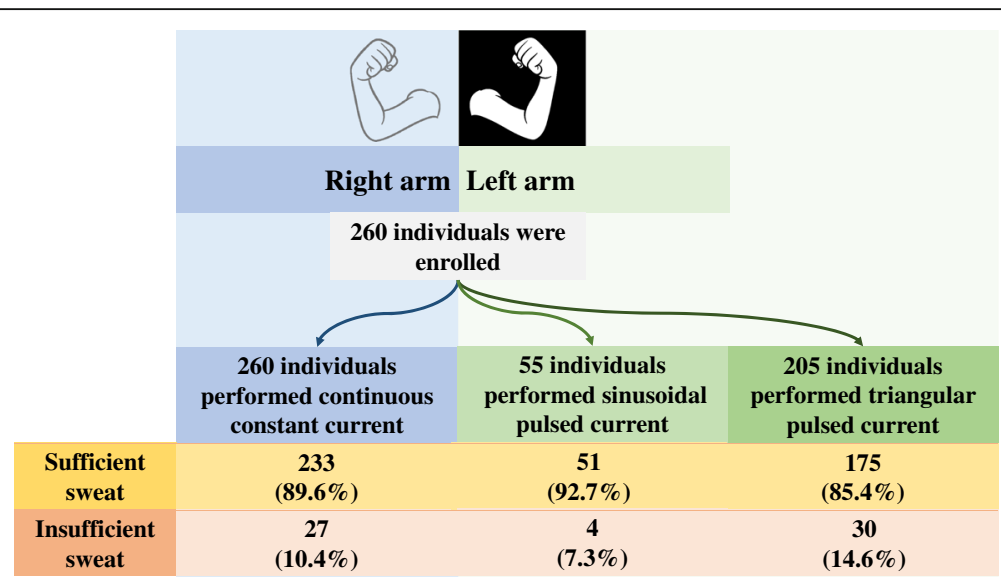

Fig. 1 Study protocol and experimental description. The study enrolled a total of 260 individuals. All the 260 individuals performed the sweat test with continuous constant current at the right arm. Also, from 260 individuals, 205 performed the sweat test with triangular pulsed current and 55 with sinusoidal pulsed current at the left arm. The comparison between continuous constant current and continuous pulsed current was based on related samples. The comparison between sinusoidal constant current and triangular constant current was based on unrelated samples

(ordinal data), respectively. The comparison of z-score of body mass index with gender and ethnicity was performed using the $x^{2}$ test. The odds ratio and the $95 \%$ confidence interval were calculated for $p$-values below 0.05 . Spearman's correlation between age, body mass index, electrode, gauze and skin electrical impedance and concentration of chloride were performed considering the CF diagnosis with continuous constant current. Also, the Spearman's correlation was used to compare the association between sweat chloride values and sweat weight (only sweat samples with sweat weight $\geq 75 \mathrm{mg}$ were analyzed) regarding all the currents analyzed.

Moreover, a Bland and Altman plot were done to represent the sweat test diagnosis difference (continuous pulsed current - continuous constant current) (y axis) and mean sweat test values between tests current [(continuous pulsed current + continuous constant current) / 2] (x axis). Also, we calculate the linear regression coefficient between sweat test diagnosis difference and mean sweat test values.

The level of significance adopted in all analyses was $\alpha=0.05$.

\section{Results}

The study analyzed 260 individuals, 141/260 (54.2\%) were female participants, $135 / 260$ (51.9\%) were Caucasians, the body mass index was $22.42 \pm 5.99 \mathrm{Kg} / \mathrm{m}^{2}$. The median age was 26 years, ranging from 0.1 to 77 years. The distribution of individuals by concentration of chloride at the sweat test was: (CF) 26/260 (10\%); (borderline) 109/260 (41.9\%); (healthy) $97 / 260$ (37.3\%); (insufficient weight in sweat below $75 \mathrm{mg}$ ) 28/260 (10.8\%) (Fig. 1).

In the study, a correlation was observed between the level of chloride and age (Spearman's Rho $=0.178$; $p$-value $=0.007$ ) and body mass index (Spearman's Rho =0.163; $p$-value $=0.014)$. However, when the correlation between the level of chloride and age and body mass index was analyzed for the different CF diagnostic groups, no significant correlation was observed ( $p$-value $>0.05)$. The correlation between electrode, gauze and skin assembly electrical impedance and age was positive with continuous constant current (Spearman's Rho $=0.262 ; p$-value $<0.001$ ); triangular pulsed current (Spearman's Rho $=0.256, p$-value $<0.001$ ); and sinusoidal pulsed current (Spearman's Rho = $0.292, p$-value $=0.032$ ).

\section{Comparison between currents (Additional file 1)}

(i) triangular pulsed current presented higher electrical impedance values when compared with sinusoidal pulsed current (Fig. 2b) ( $p$-value < 0.001). However, no difference was observed in sweat weight between continuous pulsed current ( $p$-value $=0.888$ );

(ii) triangular pulsed current presented higher electrical impedance values when compared with continuous constant current ( $p$-value < 0.001) (Fig. 2c). However, no difference was observed in sweat weight considering the triangular pulsed current and continuous constant current ( $p$-value $=0.188$ );

(iii) sinusoidal pulsed current presented lower electrical impedance (Fig. 2d) and higher sweat weight (Fig. 2e) when compared with continuous constant current $(p$-value $<0.001)$.

\section{Gender comparison for the evaluated markers (Additional file 2)}

(i) continuous constant current: male participants presented lower electrical impedance ( $p$-value $<0.001$; Fig. $3 a)$ and higher sweat weight $(p$-value $=0.008$; Fig. $3 \mathrm{~b})$ in relation to female 


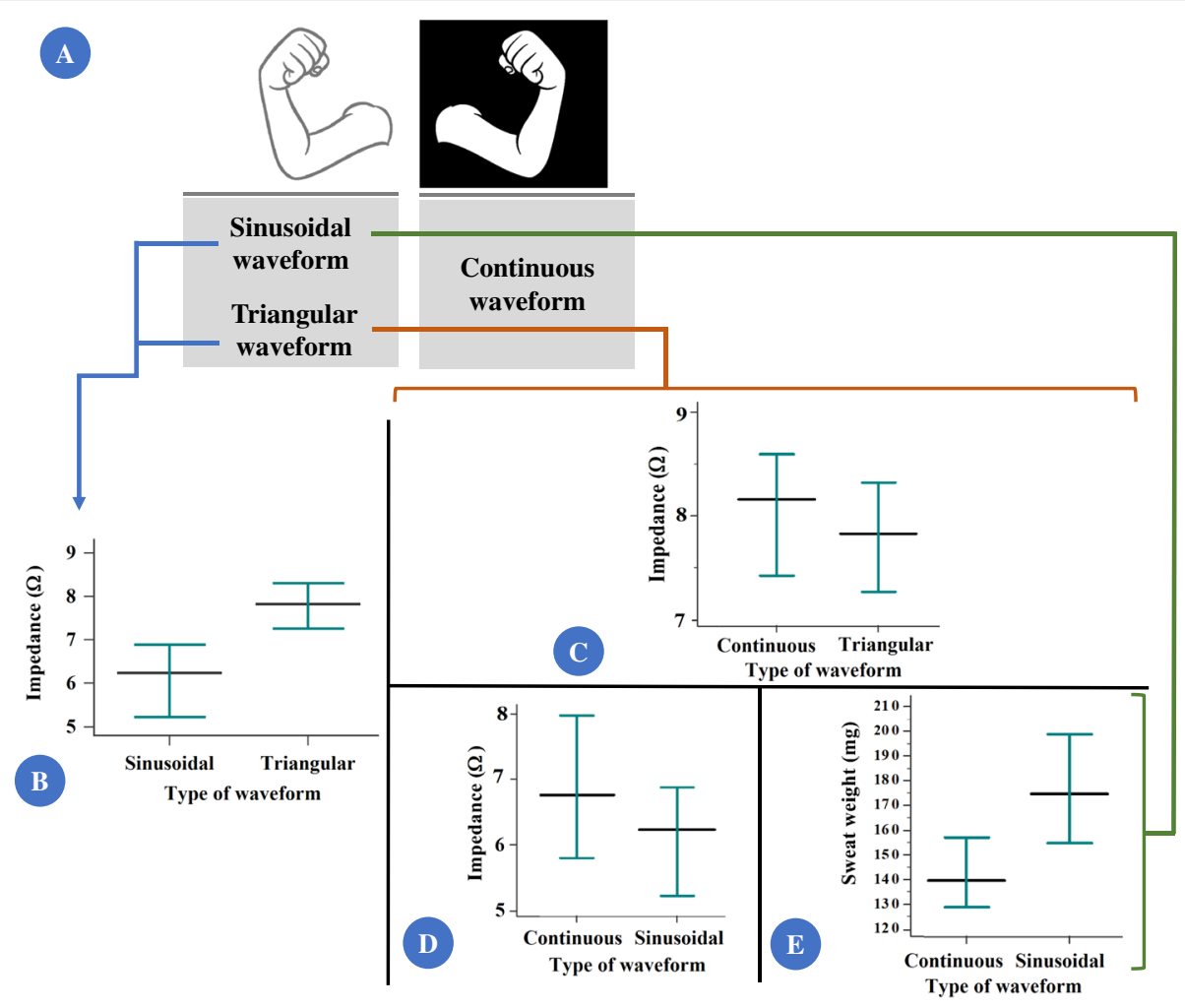

Fig. 2 The comparison between continuous constant current (CCC) and sinusoidal pulsed current (SPC) and triangular pulsed current (TPC) for electrical impedance and sweat weight showed: (i) TPC presented higher electrical impedance values when compared with SPC and CCC; (ii) SPC presented lower electrical impedance and higher sweat weight when compared with CCC. a Arm site where induction was performed using CCC and continuous pulsed current. b Comparison between SPC and TPC for electrical impedance. (SPC) $N=54 ; 6.14 \pm 2.08 ; 6.23$ (2.12 to 11.05); 5.57 to $6.71 ;$ (TPC) $N=201 ; 7.94 \pm 3.16 ; 7.82$ (1.94 to 17.76); 7.5 to 8.38. c Comparison between CCC and TPC for electrical impedance. (CCC) $N=197$; $8.9 \pm 4.8 ; 8.15$ (1.12 to 38.33); 8.23 to 9.60; (TPC) $N=197 ; 7.97 \pm 3.2 ; 7.83$ (1.94 to 17.76); 7.52 to 8.41. $\mathbf{d}$ Comparison between CCC and SPC for electrical impedance. (CCC) $N=54 ; 7.29 \pm 2.98 ; 6.76$ (2.95 to 17.11); 6.47 to 8.1 ; (SPC) $N=54 ; 6.14 \pm 2.08 ; 6.23$ (2.12 to 11.05); 5.57 to 6.71 . e Comparison between CCC and SPC for sweat weight. (CCC) $N=55 ; 146 \pm 46.1 ; 141$ (50 to 234); 133.3 to 158.8; (SPC) $N=55 ; 179 \pm 70.2 ; 176$ (46 to 433); 159.7 to 197.1. All $p$-values were below 0.001. Data are presented as: number of individuals; mean \pm standard deviation; median (minimum to maximum); confidence interval for the mean value. Statistical analysis conducted through Wilcoxon signed-rank test and Mann-Whitney $U$ test of independent samples. Alpha $=0.05$. The currents are shown as $\Omega$ using the following equation: $\left[Z=V_{\text {RMS }} / I_{\text {RMS }}(\Omega)\right]$; $Z=$ composite impedance $(\Omega) ; V_{\text {RMS }}=$ effective voltage measured (volts root mean square); $I_{\text {RMS }}=$ effective current measured (current root mean square). Also, the sweat weight is shown as milligrams. Only the associations with $p$-value $<0.05$ was presented as figure

participants. Body mass index in $\mathrm{Kg} / \mathrm{m}^{2}$ was the same for both groups ( $p$-value $=0.085$ ); however, different values were obtained with the z-score analysis $(p$-value $=0.011)$ (Table 1$)$;

(ii) sinusoidal pulsed current: male participants presented higher sweat weight (Fig. 3c) in relation to female participants $(p$-value $=0.007)$. However, no difference was observed in electrical impedance $(p$-value $=0.381)$ and body mass index $\left(\mathrm{Kg} / \mathrm{m}^{2}-p\right.$-value $=0.287 ; \mathrm{z}$-score $-p$-value $\left.=0.733\right)$ in gender comparison;

(iii) triangular pulsed current: male participants presented lower electrical impedance ( $p$-value < 0.003; Fig. 3d) and higher sweat weight ( $p$-value $=0.008 ;$ Fig. $3 e)$ in relation to female participants. Body mass index in $\mathrm{Kg} / \mathrm{m}^{2}$ was the same for both groups ( $p$-value $=0.202)$; however, different values were obtained with the $\mathrm{z}$-score analysis $(p$-value $=0.012)($ Table 1$)$.

\section{Ethnicity comparison (Caucasians and non-Caucasians) for the evaluated markers (Additional file 3)}

(i) continuous constant current: body mass index in $\mathrm{Kg} / \mathrm{m}^{2}$ was higher in the group of Caucasians ( $p$-value $=0.001)$, and different values were obtained for the groups with the z-score analysis $(p$-value $=0.027)($ Fig. $4 \mathrm{a}$ and Table 1). However, no difference was observed in electrical impedance $(p$-value $=0.653)$ and sweat weight $(p$-value $=0.141)$;

(ii) sinusoidal pulsed current: electrical impedance was lower in the group of Caucasians ( $p$-value $=0.037$ ) (Fig. 4b). However, no difference was observed in 


\section{ii}

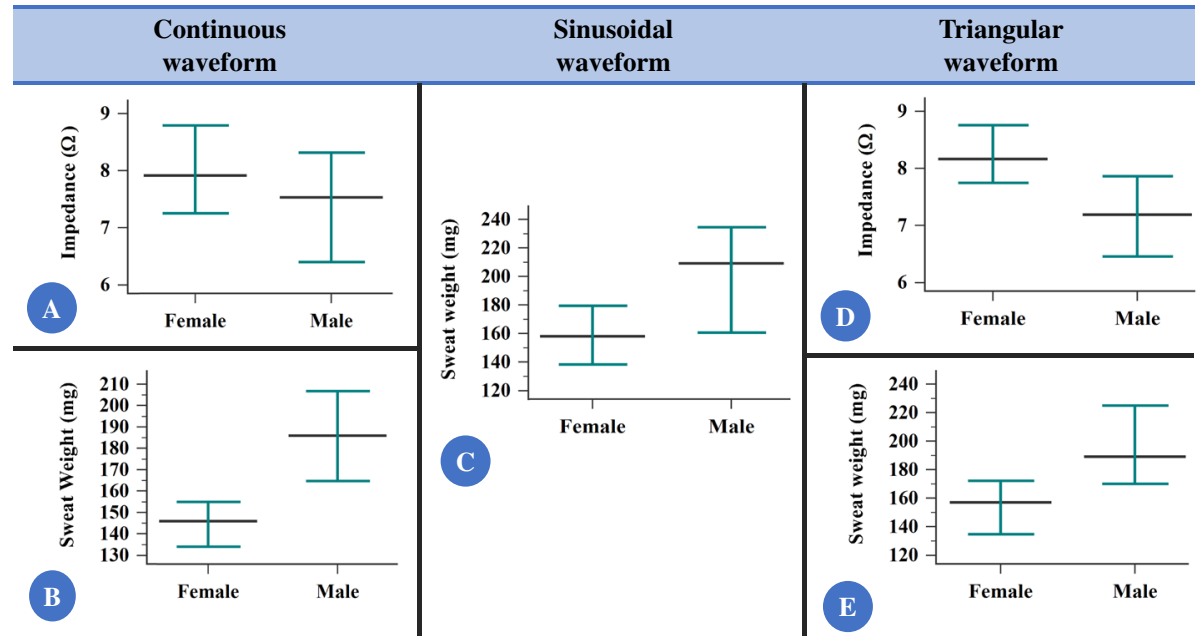

Fig. 3 The comparison between female and male participants for the values of electrical impedance and sweat weight, according to the current applied showed: male presented lower electrical impedance [continuous constant current (CCC), triangular pulsed current (TPC)] and higher sweat weight [CCC, sinusoidal pulsed current (SPC), TPC] in relation to female. a Comparison for electrical impedance with CCC. (Female) $\mathrm{N}=136$; $9.3 \pm 4.94 ; 7.91$ (1.12 to 38.33); 8.46 to 10.14; (Male) $N=116 ; 7.67 \pm 3.75 ; 7.53$ (2.3 to 22.29); 6.98 to 8.36 . b Comparison for sweat weight with CCC. (Female) $N=141 ; 155 \pm 73 ; 146$ (0 to 425); 142 to 167 ; (Male) $N=119 ; 193 \pm 104 ; 186$ (3 to 577); 174 to 211 . c Comparison for sweat weight with SPC. (Female) $N=30 ; 153 \pm 55 ; 158$ (46 to 267); 132 to 174; (Male) $N=25 ; 208 \pm 74 ; 209$ (97 to 433); 177 to 238. d Comparison for electrical impedance with TPC. (Female) $N=109 ; 8.57 \pm 3.17 ; 8.16$ (2.33 to 17.76); 7.97 to 9.17; (Male) $N=92 ; 7.2 \pm 2.98 ; 7.18$ (1.94 to 16.33 ); 6.58 to 7.81. e Comparison for sweat weight with TPC. (Female) $N=109 ; 164 \pm 88 ; 157$ (6 to 535); 148 to 181 ; (Male) $N=92 ; 206 \pm 115 ; 189$ (9 to 699 ); 182 to 229. All $p$-values were below 0.003. Data are presented in legend as: number of individuals; mean \pm standard deviation; median (minimum to maximum); confidence interval for the mean value; and in figure as median (black line) and 95\% confidence interval (green line). Statistical analysis conducted through Wilcoxon signed-rank test and Mann-Whitney $U$ test of independent samples. Alpha $=0.05$. The currents are shown as $\Omega$ using the following equation: $\left[Z=V_{\text {RMS }} / I_{R M S}(\Omega)\right] ; Z=$ composite impedance $(\Omega) ; V_{R M S}=$ effective voltage measured (volts root mean square); $I_{\text {RMS }}=$ effective current measured (current root mean square). Also, the sweat weight is shown as milligrams. There is no impedance figure with sinusoidal pulsed current because the $p$-value $>0.05$ was observed

sweat weight $(p$-value $=0.214)$ and body mass index $\left(\mathrm{Kg} / \mathrm{m}^{2}-p\right.$-value $=0.861 ; \mathrm{z}$-score $-p$-value $\left.=0.351\right) ;$

(iii) triangular pulsed current: body mass index in $\mathrm{Kg} / \mathrm{m}^{2}$ was higher in the group of Caucasians ( $p$-value $=0.001)$, and different values were obtained for the groups with the z-score analysis $(p$-value $=0.007)($ Fig. $4 \mathrm{c}$ and Table 1$)$. However, no difference was observed in electrical impedance $(p$-value $=0.508)$ and sweat weight $(p$-value $=0.141)$.

\section{Comparison of number of exams with insufficient sweat weight and sweat test results between continuous constant current and sinusoidal and triangular continuous pulsed current}

No association was observed between sweat weight when compared with different currents ( $p$-value $>0.05$ ) (Table 2). However, the sweat test outcome was different according to the current applied and sweat weight achieved. Data are presented in Tables 3, 4, 5 and 6, which includes the Kappa agreement index calculation. Also, when we compared the triangular pulsed current and sinusoidal pulsed current regarding the difference between continuous constant current and continuous pulsed current, and the sinusoidal pulsed current showed a higher amount of sweat weight $(p$-value $=0.02)$ (Fig. 5). Moreover, there was a correlation (Spearman's Rho) between sweat chloride values (CF-diagnosis) and the sweat weight of - 0.482 (95\% confidence interval for Rho $=-0.549$ to -0.409$)$ ( $p$-value < 0.0001) (Fig. 6a-d). In addition, we included the Fig. 7 showing the results from Bland and Altman plot considering the agreement between the sweat chloride values achieved from continuous pulsed current (Fig. 7a) [sinusoidal pulsed current (Fig. 7b) and triangular pulsed current (Fig. 7c)] and continuous constant current. In the data, we found there is no proportional bias in our data and mean values are unrelated and only explain less than $8 \%$ of the variation.

\section{Discussion}

Our findings show that the type of current used to induce sweat can alter the electrical impedance created among the electrode, gauze and skin components. This 
Table 1 Comparison of body mass index adjusted by z-score of age for gender and ethnicity for continuous constant current and sinusoidal and triangular continuous pulsed current

\begin{tabular}{|c|c|c|c|c|c|}
\hline \multirow[t]{2}{*}{ Body mass index group } & & \multicolumn{3}{|l|}{ Gender } & \multirow[t]{2}{*}{$p$-value } \\
\hline & & Female & Male & Total & \\
\hline \multirow[t]{4}{*}{ Continuous constant current } & Eutrophic & 91 & 61 & 152 & \multirow[t]{4}{*}{0.011} \\
\hline & Slenderness + accentuated slenderness ${ }^{a}$ & 7 & 18 & 25 & \\
\hline & Overweight + obesity + serious obesity ${ }^{\mathrm{b}}$ & 42 & 39 & 81 & \\
\hline & Total & 140 & 118 & 258 & \\
\hline \multirow[t]{4}{*}{ Triangular continuous pulsed current } & Eutrophic & 78 & 52 & 130 & \multirow[t]{4}{*}{0.012} \\
\hline & Slenderness + accentuated slenderness ${ }^{c}$ & 5 & 15 & 20 & \\
\hline & Overweight + obesity + serious obesity ${ }^{d}$ & 27 & 26 & 53 & \\
\hline & Total & 110 & 93 & 203 & \\
\hline \multirow[t]{2}{*}{ Body mass index group } & & \multicolumn{3}{|c|}{ Caucasians } & $p$-value \\
\hline & & Yes & No & Total & \\
\hline \multirow[t]{4}{*}{ Continuous constant current } & Eutrophic & 68 & 84 & 152 & \multirow[t]{4}{*}{0.027} \\
\hline & Slenderness + accentuated slenderness ${ }^{e}$ & 14 & 11 & 25 & \\
\hline & Overweight + obesity + serious obesity ${ }^{f}$ & 51 & 30 & 81 & \\
\hline & Total & 133 & 125 & 258 & \\
\hline \multirow[t]{4}{*}{ Triangular continuous pulsed current } & Eutrophic & 52 & 78 & 120 & \multirow[t]{4}{*}{0.007} \\
\hline & Slenderness + accentuated slenderness ${ }^{9}$ & 12 & 8 & 20 & \\
\hline & Overweight + obesity + serious obesity ${ }^{h}$ & 34 & 19 & 53 & \\
\hline & Total & 98 & 105 & 203 & \\
\hline
\end{tabular}

Body mass index was adjusted by $z$-score (age); OR, odds ratio; $95 \% \mathrm{Cl}$, confidence interval of $95 \%$. The calculation of odds ratio used the degree of eutrophic as its parameter. Statistical analysis conducted by $x^{2}$ test. Alpha $=0.05$. Statistically significant data are in bold ${ }^{\mathrm{a}} \mathrm{OR}=0.261 ; 95 \% \mathrm{Cl}=0.103$ to 0.662

${ }^{\mathrm{b}} \mathrm{OR}=0.722 ; 95 \% \mathrm{Cl}=0.419$ to 1.243

$\mathrm{C} \mathrm{OR}=0.222 ; 95 \% \mathrm{Cl}=0.076$ to 0.649

${ }^{\mathrm{d}} \mathrm{OR}=0.692 ; 95 \% \mathrm{Cl}=0.364$ to 1.317

${ }^{\mathrm{e}} \mathrm{OR}=1.572 ; 95 \% \mathrm{Cl}=0.671$ to 3.685

f $\mathrm{OR}=2.1 ; 95 \% \mathrm{Cl}=1.208$ to 3.65

${ }^{\mathrm{g}} \mathrm{OR}=2.25 ; 95 \% \mathrm{Cl}=0.861$ to 5.882

${ }^{\mathrm{h}} \mathrm{OR}=2.684 ; 95 \% \mathrm{Cl}=1.385$ to 5.204

fact influences the induction of sweat and, consequently, the sweat weight, promoting a variability at the sweat test results. In addition, gender and ethnicity may influence the natural variation of sweat test values and should be considered when conducting the test [25-27].

Few studies are available taking into account the different types of currents to promote the skin sweat induction in CF. In a previous study from our group we observed that the first stage of the sweat test (sweat induction) presents particularities that need a better investigation and technique detailing [23].

The sweat test has been considered, since the 1950s, as the gold standard for the diagnosis of CF $[1,28,29]$. However, still today, numerous studies have shown that this test involves challenges, requiring sweat test standardization [2, 11-13, 30-33]. Like other countries, Brazil, including in CF reference centers, presents low knowledge about how to conduct the sweat test protocol and the accepted methods to perform chloride dosage [20].
To facilitate the sweat test conduction in Brazil, our research group recently conducted a study in which the sweat induction was evaluated through pilocarpine iontophoresis using a device developed by the biomedical engineering team of the university. In the study, we evaluated: (i) the outcomes from the use of continuous constant current and triangular pulsed current; (ii) amount of sweat induced by different currents; (iii) ideal time of sweat induction and collection; (iv) electrode, gauze and skin electrical impedance for the different currents; (v) side effects. Hence, a better performance of the sweat test was obtained with one $\mathrm{mA}$ current, $1000 \mathrm{~Hz}$ frequency (for triangular pulsed current), 10 and $30 \mathrm{~min}$ for induction and collection, respectively. In addition, no side effects were observed that would make the developed device unfeasible [23].

Based on the previous findings, in this study, we proposed to evaluate a larger sample of participants and to analyze sweat induction at different ages, and in different 


\section{Ethnicity}

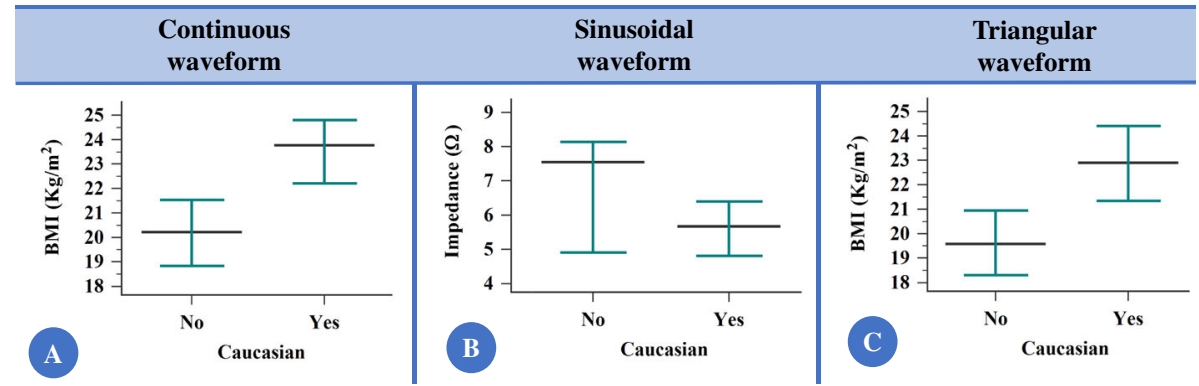

Fig. 4 The comparison between Caucasians and non-Caucasians for the values of electrical impedance and body mass index, according to the current applied showed that the body mass index was higher in the group of Caucasians [continuous constant current (CCC) and triangular pulsed current (TPC)], and the sinusoidal pulsed current (SPC) was associated with lower electrical impedance in the group of Caucasians. a Body mass index with the application of CCC. (Non-Caucasians) $N=125 ; 21.26 \pm 5.7 ; 20.21$ (11.06 to 42.29); 20.25 to 22.27; (Caucasians) $N=133 ; 23.5 \pm$ 6.07; 23.72 ( 0 to 38.2); 22.46 to 24.55; ( $p$-value $=0.001$ ). b Electrical impedance with the application of SPC. (Non-Caucasians) $N=20 ; 6.98 \pm 2.36$; 7.55 (3.19 to 11.05); 5.87 to 8.09; (Caucasians) $N=34 ; 5.64 \pm 1.74 ; 5.66$ (2.12 to 9.62); 5.03 to 6.25. ( $p$-value $=0.037$ ). c Electrical impedance with the application of TPC. (Non-Caucasians) $N=105 ; 20.6 \pm 5.06 ; 19.57$ (11.06 to 34.84); 19.61 to 21.58; (Caucasians) $N=98 ; 23.14 \pm 6.19 ; 22.9$ (0 to 38.2$)$; 21.89 to 24.38 . ( $p$-value $=0.001$ ). Data are presented in legend as: number of individuals; mean \pm standard deviation; median (minimum to maximum); confidence interval for the mean value; confidence interval for the mean value; and in figure as median (black line) and $95 \%$ confidence interval (green line). Statistical analysis conducted through Wilcoxon signed-rank test and Mann-Whitney $U$ test of independent samples. Alpha $=0.05$. The currents are shown as $\Omega$ using the following equation: $\left[Z=V_{\text {RMS }} / I_{\text {RMS }}(\Omega)\right] ; Z=$ composite impedance $(\Omega) ; V_{\text {RMS }}=$ effective voltage measured (volts root mean square); $I_{R M S}=$ effective current measured (current root mean square). Also, the body mass index is shown as weight $(\mathrm{Kg}) /$ height $^{2}(\mathrm{~m})$. Only the associations with $p$-value $<0.05$ was presented as figure

genders and ethnic groups, comparing the sinusoidal pulsed current, triangular pulsed current and continuous constant current. At the sweat test, the amount of sweat produced is directly related to the delivery of pilocarpine in the skin, and when the induction by iontophoresis is incorrectly performed, the induced sweat may be insufficient and can alter the final result of the diagnosis. Aggravation and risks arising from the electric currents can be observed due to errors during sweat induction, with the possibility of burns, especially in newborns.

Our study showed that the electrode, gauze and skin assembly electrical impedance, providing a larger or smaller amount of sweat, in an inverse association with sweat weight, varied according to the type of current applied. The sinusoidal pulsed current resulted in lower electrical impedance and higher sweat production, when compared with continuous constant current and triangular pulsed current. However, although the sinusoidal pulsed current resulted in lower electrical impedance and higher sweat production, all currents evaluated were able to induce sufficient sweat for the electrolyte analysis. In addition, in our sample, electrical impedance showed a positive correlation with age with all types of currents applied (continuous constant current - Spearman's Rho $=0.262 ; p$-value $<$

Table 2 Comparison of number of exams with insufficient sweat weight (below 75 mg) between continuous constant current and sinusoidal and triangular continuous pulsed current

\begin{tabular}{|c|c|c|c|c|}
\hline & \multirow[b]{2}{*}{ Sweat weight } & \multicolumn{3}{|c|}{ Continuous constant current } \\
\hline & & Sufficient & Insufficient & $p$-value \\
\hline \multirow[t]{2}{*}{ Sinusoidal pulsed current } & Sufficient & $49(89.1 \%)$ & $3(5.5 \%)$ & \multirow[t]{2}{*}{$0.655^{\mathrm{a}}$} \\
\hline & Insufficient & $2(3.6 \%)$ & $1(1.8 \%)$ & \\
\hline \multirow[t]{2}{*}{ Triangular pulsed current } & Sufficient & $172(83.9 \%)$ & $9(4.4 \%)$ & \multirow[t]{2}{*}{$0.523^{b}$} \\
\hline & Insufficient & $13(6.3 \%)$ & $11(5.4 \%)$ & \\
\hline \multirow[t]{2}{*}{ Continuous pulsed current } & Sufficient & $221(85 \%)$ & $12(4.6 \%)$ & \multirow[t]{2}{*}{$0.333^{c}$} \\
\hline & Insufficient & $15(5.8 \%)$ & $12(4.6 \%)$ & \\
\hline
\end{tabular}

Statistical analysis conducted through McNemar's tests. Alpha $=0.05$

${ }^{a}$ Number of observed agreements $=50(90.91 \%) ;$ Number of agreements expected by chance $=48.4(88.07 \%) ;$ Kappa $=0.238 ; \mathrm{SE}$ of kappa $=0.232 ; 95 \%$ confidence interval $(95 \% \mathrm{Cl})=-0.217$ to 0.693 ; strength of agreement $=$ fair

${ }^{\mathrm{b}}$ Number of observed agreements $=183(93.85 \%)$; number of agreements expected by chance $=163.9(84.04 \%) ; \mathrm{Kappa}=0.614 ; \mathrm{SE}$ of $\mathrm{kappa}=0.101 ; 95 \% \mathrm{Cl}=0.416$ to 0.813 ; strength of agreement $=$ good

${ }^{\mathrm{c}}$ Number of observed agreements $=233(89.62 \%) ;$ number of agreements expected by chance $=214(82.3 \%) ; \mathrm{Kappa}=0.413 ; \mathrm{SE}$ of $\mathrm{kappa}=0.093 ; 95 \% \mathrm{Cl}=0.232$ to 0.595 ; strength of agreement $=$ moderate. As shown in the table, the minor prevalence of insufficient sweat weight occurred for sinusoidal pulsed current (1.8\%) 
Table 3 Comparison of sweat test result between continuous constant current and sinusoidal and triangular continuous pulsed current

\begin{tabular}{|c|c|c|c|c|c|}
\hline \multirow[t]{2}{*}{ Sweat test result } & & \multicolumn{4}{|c|}{ Continuous constant current } \\
\hline & & Cystic fibrosis & Borderline & Normal & $p$-value \\
\hline \multirow[t]{3}{*}{ Sinusoidal pulsed current } & Cystic fibrosis & 4 & 1 & 0 & $0.008^{a}$ \\
\hline & Borderline & 0 & 16 & 1 & \\
\hline & Normal & 1 & 11 & 15 & \\
\hline \multirow[t]{3}{*}{ Triangular pulsed current } & Cystic fibrosis & 14 & 5 & 0 & $0.423^{b}$ \\
\hline & Borderline & 6 & 49 & 12 & \\
\hline & Normal & 0 & 16 & 62 & \\
\hline \multirow[t]{3}{*}{ Continuous pulsed current } & Cystic fibrosis & 18 & 6 & 0 & $0.033^{c}$ \\
\hline & Borderline & 6 & 65 & 13 & \\
\hline & Normal & 1 & 27 & 77 & \\
\hline
\end{tabular}

Statistical analysis conducted through Wilcoxon signed-rank test (ordinal data). Alpha $=0.05$

${ }^{a}$ Number of observed agreements $=35$ (71.43\%); number of agreements expected by chance $=19(38.86 \%) ;$ Kappa $=0.533 ;$ SE of kappa $=0.101 ; 95 \%$ confidence interval $(95 \% \mathrm{Cl})=0.335$ to 0.73 ; strength of agreement $=$ moderate; weighted Kappa $=0.563$; strength of agreement $=$ moderate

${ }^{\mathrm{b}}$ Number of observed agreements $=125(76.22 \%)$; number of agreements expected by chance $=66.1(40.31 \%) ; \mathrm{Kappa}=0.602 ; \mathrm{SE}$ of $\mathrm{kappa}=0.056 ; 95 \% \mathrm{Cl}=0.492$ to 0.711 ; strength of agreement $=$ good; weighted Kappa $=0.664$; strength of agreement $=$ good

${ }^{c}$ Number of observed agreements $=160(75.12 \%)$; number of agreements expected by chance $=85.8(40.3 \%) ; \mathrm{Kappa}=0.583 ; \mathrm{SE}$ of $\mathrm{kappa}=0.05 ; 95 \% \mathrm{Cl}=0.485$ to

0.681 ; strength of agreement $=$ moderate; weighted Kappa $=0.639$; strength of agreement $=$ good. Statistically significant data are in bold. Additional analysis is shown as Fig. 7

0.001; triangular pulsed current - Spearman's Rho $=0.256$, $p$-value < 0.001 ; sinusoidal pulsed current - Spearman's Rho $=0.292, p$-value $=0.032$ )

In the evaluation of iontophoresis for the delivery of drugs to the skin, continuous constant current was the most frequent current [34]. However, according to other authors, the use of continuous constant current may result in permanent electrode, gauze and skin assembly polarization during sweat induction and reduce the efficiency of iontophoretic administration in proportion to the current application time, by increasing the impedance of the electrode-skin assembly, and this may cause burning and redness [35-37].

In contrast, some authors have shown that continuous pulsed current can minimize the presence of polarization $[37,38]$. To prevent the side effects of continuous constant current, some researchers have studied several types of drugs and evaluated the efficacy of continuous pulsed current, at different waveforms, in skin permeation. However, no consensus has been achieved regarding the most effective type of current.

What is known so far is that for continuous pulsed current, the waveform influences the permeation of drugs through the skin. For instance, (a) the absorption of luteinizing hormone-releasing hormone using continuous constant current $\left(0.764 \mathrm{~mA} / \mathrm{cm}^{2}\right)$ and sinusoidal and rectangular continuous pulsed current $(0.764 \mathrm{~mA} /$ $\mathrm{cm}^{2}$ and one $\mathrm{kHz}$ ) did not produce different values for the permeation flux. However, the flow caused by triangular waveforms was lower than that of continuous constant current [39]; (b) the permeation flow of some drugs is efficient with the use of sinusoidal, trapezoidal and rectangular waveforms $\left(0.33 \mathrm{~mA} / \mathrm{cm}^{2}\right.$ and two $\left.\mathrm{kHz}\right)$ [40]; (c) the skin permeability of amino acids (lysine and glutamic acid) using current density of $0.5 \mathrm{~mA} / \mathrm{cm}^{2}$ and $2.5 \mathrm{kHz}$ frequency were the same in rectangular and sinusoidal waveforms [41]; (d) the permeability of iondomethacin was better with continuous pulsed current at frequencies lower than $100 \mathrm{~Hz}$ and with rectangular and sinusoidal waveforms [42].

On the other hand, square waveform was more efficient in promoting the permeation of the granisetron by iontophoresis than the continuous constant current [37]. The higher efficiency of square pulsed current in relation to continuous constant current can be explained by the amount of electrical permeation load that is reduced by half with square continuous pulsed current. Square continuous pulsed current was also considered less harmful to the skin.

Unlike previous studies, our study used triangular pulsed current, sinusoidal pulsed current, and a fixed value of one $\mathrm{mA}$. Although the sinusoidal pulsed current presented lower electrical impedance when compared with the triangular pulsed current and continuous constant current, all tested currents were able to provide sufficient sweat weight for the electrolyte analysis.

In our previous study, the triangular pulsed current presented lower electrical impedance values when compared with continuous constant current, but without difference in sweat weight [23]. On the other hand, in this study, we identified that the sinusoidal pulsed current presented the lowest electrical impedance, which was concomitant to the greatest sweat weight obtained. The results of our two 
Table 4 Individuals included in the study who presented different results in the cystic fibrosis (CF) classification according to the chloride dose

\begin{tabular}{|c|c|c|c|c|c|c|}
\hline \multirow[b]{2}{*}{ Type of current } & \multicolumn{3}{|c|}{ Continuous pulsed current } & \multicolumn{3}{|c|}{ Continuous constant current } \\
\hline & Sweat weight & Chloride & Classification & Sweat weight & Chloride & Classification \\
\hline Sinusoidal & 135 & 30.02 & Borderline & 142 & 21.42 & No \\
\hline Triangular & 216 & 33.1 & Borderline & 426 & 12.23 & No \\
\hline Triangular & 284 & 30.26 & Borderline & 236 & 20.36 & No \\
\hline Triangular & 185 & 49.54 & Borderline & 189 & 21.56 & No \\
\hline Triangular & 168 & 30.26 & Borderline & 225 & 22.72 & No \\
\hline Triangular & 122 & 41.48 & Borderline & 168 & 23.84 & No \\
\hline Triangular & 194 & 31.52 & Borderline & 214 & 23.86 & No \\
\hline Triangular & 160 & 31.75 & Borderline & 162 & 25.09 & No \\
\hline Triangular & 227 & 36.04 & Borderline & 239 & 25.7 & No \\
\hline Triangular & 129 & 31.4 & Borderline & 144 & 28.17 & No \\
\hline Triangular & 145 & 34.98 & Borderline & 212 & 28.9 & No \\
\hline Triangular & 135 & 31.08 & Borderline & 187 & 29.15 & No \\
\hline Triangular & 174 & 35.08 & Borderline & 239 & 29.98 & No \\
\hline Triangular & 107 & 94.45 & $\mathrm{CF}$ & 301 & 37.64 & Borderline \\
\hline Triangular & 91 & 66.53 & CF & 128 & 47.48 & Borderline \\
\hline Triangular & 102 & 108.94 & $\mathrm{CF}$ & 141 & 50.34 & Borderline \\
\hline Triangular & 122 & 66.37 & $\mathrm{CF}$ & 95 & 53.13 & Borderline \\
\hline Sinusoidal & 84 & 60.02 & CF & 89 & 56.67 & Borderline \\
\hline Sinusoidal & 144 & 21.13 & No & 134 & 30.25 & Borderline \\
\hline Sinusoidal & 199 & 15.37 & No & 133 & 30.47 & Borderline \\
\hline Sinusoidal & 248 & 24.79 & No & 231 & 31 & Borderline \\
\hline Sinusoidal & 236 & 26.02 & No & 128 & 31.65 & Borderline \\
\hline Sinusoidal & 157 & 19.35 & No & 127 & 31.89 & Borderline \\
\hline Sinusoidal & 212 & 19.26 & No & 126 & 32.14 & Borderline \\
\hline Sinusoidal & 117 & 25.94 & No & 126 & 32.14 & Borderline \\
\hline Sinusoidal & 149 & 27.24 & No & 129 & 39.25 & Borderline \\
\hline Sinusoidal & 140 & 28.97 & No & 146 & 41.15 & Borderline \\
\hline Sinusoidal & 175 & 29.71 & No & 221 & 41.62 & Borderline \\
\hline Sinusoidal & 305 & 13.51 & No & 186 & 43.81 & Borderline \\
\hline Triangular & 535 & 9.84 & No & 101 & 30 & Borderline \\
\hline Triangular & 272 & 22.65 & No & 292 & 30.05 & Borderline \\
\hline Triangular & 163 & 18.7 & No & 97 & 31.22 & Borderline \\
\hline Triangular & 241 & 16.99 & No & 160 & 31.75 & Borderline \\
\hline Triangular & 206 & 19.81 & No & 106 & 31.75 & Borderline \\
\hline Triangular & 320 & 19.35 & No & 159 & 31.94 & Borderline \\
\hline Triangular & 225 & 18.17 & No & 157 & 32.34 & Borderline \\
\hline Triangular & 143 & 28.37 & No & 89 & 34 & Borderline \\
\hline Triangular & 229 & 26.8 & No & 178 & 34.3 & Borderline \\
\hline Triangular & 175 & 29.07 & No & 174 & 35.08 & Borderline \\
\hline Triangular & 250 & 24.6 & No & 218 & 37.49 & Borderline \\
\hline Triangular & 180 & 22.62 & No & 130 & 38.96 & Borderline \\
\hline Triangular & 102 & 29.71 & No & 156 & 39.06 & Borderline \\
\hline Triangular & 178 & 22.87 & No & 176 & 40.47 & Borderline \\
\hline Triangular & 136 & 29.81 & No & 97 & 41.63 & Borderline \\
\hline Triangular & 362 & 11.45 & No & 120 & 50.6 & Borderline \\
\hline Triangular & 111 & 54.65 & Borderline & 101 & 60 & CF \\
\hline Triangular & 268 & 57.47 & Borderline & 200 & 61.2 & $\mathrm{CF}$ \\
\hline Triangular & 114 & 53.23 & Borderline & 147 & 62.12 & $\mathrm{CF}$ \\
\hline Triangular & 203 & 53.37 & Borderline & 150 & 67.66 & $\mathrm{CF}$ \\
\hline Triangular & 189 & 59.3 & Borderline & 140 & 72.42 & $\mathrm{CF}$ \\
\hline Triangular & 175 & 52.27 & Borderline & 106 & 76.27 & $\mathrm{CF}$ \\
\hline Sinusoidal & 180 & 28.27 & No & 80 & 63 & $\mathrm{CF}$ \\
\hline
\end{tabular}

The colors indicate the changes in the cystic fibrosis diagnosis classification, according to the chloride dose. The table also shows the obtained sweat weight value, which is associated with the chloride dilution in the amount of sweat collected and may change the sweat test result. The sweat test is defined in mmol/L. The sweat weight is defined in mg. Using different currents, we achieved different results in the classification of the sweat test, mainly, considering the borderline value. Also, in the present study, we included only individuals with clinical suspicion of cystic fibrosis, but sometimes, without a close diagnosis (absence of two CFTR mutations and/or two sweat tests $\geq 60 \mathrm{mmol} / \mathrm{L}$ ). In this context, we found a lot of variability that could be a reflex of the patient enrolled in the studied sample. Finally, all the currents used to induce sweating showed a close capacity to induce the sweat weight above $75 \mathrm{mg}$ 
Table 5 Comparison of sweat weight values ( $\mathrm{mg}$ ) between pulsed current and continuous current, considering the sweat test classification according to the chloride dose

\begin{tabular}{|c|c|c|c|c|c|}
\hline \multicolumn{2}{|c|}{ Continuous pulsed current } & \multicolumn{2}{|c|}{ Continuous constant current } & \multirow{2}{*}{$\frac{N}{1}$} & \multirow{2}{*}{$\frac{p \text {-value }}{-}$} \\
\hline Non-cystic fibrosis & 108 & Cystic fibrosis & 80 & & \\
\hline \multirow[t]{2}{*}{ Borderline } & $175 \pm 46$ & Non-cystic fibrosis & $214 \pm 72$ & 13 & 0.009 \\
\hline & 168 (122 to 284$)$ & & $212(142$ to 426$)$ & & \\
\hline \multirow[t]{2}{*}{ Cystic fibrosis } & $101 \pm 15$ & Borderline & $151 \pm 87$ & 5 & 0.138 \\
\hline & 102 (84 to 122$)$ & & 128 (89 to 301$)$ & & \\
\hline \multirow[t]{2}{*}{ Non-cystic fibrosis } & $215 \pm 90$ & Borderline & $154 \pm 46$ & 27 & $<0.001$ \\
\hline & 199 (102 to 535$)$ & & 146 (89 to 292$)$ & & \\
\hline \multirow[t]{2}{*}{ Borderline } & $181 \pm 62$ & Cystic fibrosis & $141 \pm 36$ & 6 & 0.075 \\
\hline & 182 (111 to 269$)$ & & 143 (101 to 20$)$ & & \\
\hline
\end{tabular}

Statistical analysis conducted through Wilcoxon signed-rank test. Statistically significant data are in bold. N, number of individuals included in each category - It does not reflect the number of individuals included in the performed experiments. Data are presented in table as: number of individuals; mean \pm standard deviation; median (minimum to maximum), except for the first line where the absolute value is shown

studies (the one of 2014 and this study) favor the use of continuous pulsed current to obtain sweat for the sweat test, and that the sinusoidal pulsed current is probably more efficient than the triangular pulsed current.

Further studies on sweat induction with iontophoresis and pilocarpine using continuous pulsed current should be conducted to obtain more consistent information on sweat induction and the use of different types of currents.

The literature describes that skin characteristics change with age, and that such changes have an impact on skin impedance and resistance, making it difficult to deliver medication during electrical stimulation. With aging, the skin tends to become dehydrated, dry, and more resistant, which are obstacles to sweat induction during stimulation [43-45]. These factors may explain the positive correlation between electrical impedance and age observed in our sample, regardless of the current applied.

In our study, the age of the participants did not influence the collection of sufficient or insufficient amount of sweat to measure chloride at the sweat test ( $p$-value for continuous constant current, sinusoidal pulsed current and triangular pulsed current were 0.098, 0.661 , and 0.468 , respectively).

Also known is the fact that high body mass index can hinder drug permeation by iontophoresis, and it may also change the pilocarpine permeation in the skin and then reduce sweat production. This fact may be associated with the characteristic poor electrical conduction of adipose tissues [21, 42, 46]. However, in our study, most participants did not present high body mass index, which could change the results obtained. Higher body mass index values were identified in Caucasians when compared with non-Caucasians.

It is also known that the stratum corneum is the outermost layer of the skin and, besides the presence of lipids, keratin restricts the transport of compounds through the skin, for example, pilocarpine [43, 47, 48]. The literature reports that increased keratin concentration of the skin is associated with difficult sweat induction [49-51]. However, in our study, electrical impedance was observed in Caucasians only with sinusoidal pulsed current application.

Table 6 Comparison of sweat weight values $(\mathrm{mg})$ between pulsed current and continuous current, considering if an increase or reduction was observed in chloride concentration between pulsed current and continuous current

\begin{tabular}{|c|c|c|c|c|}
\hline & $\begin{array}{l}\text { Continuous pulsed } \\
\text { current }\end{array}$ & $\begin{array}{l}\text { Continuous constant } \\
\text { current }\end{array}$ & $\mathrm{N}$ & $p$-value \\
\hline \multirow{2}{*}{ 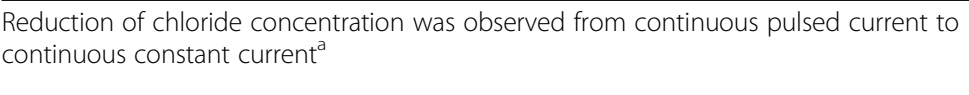 } & $154 \pm 52$ & $197 \pm 80$ & \multirow[t]{2}{*}{18} & \multirow[t]{2}{*}{0.004} \\
\hline & 140 (84 to 284) & 0.188 (89 to 426$)$ & & \\
\hline \multirow{2}{*}{$\begin{array}{l}\text { Increase of chloride concentration was observed from continuous pulsed current to } \\
\text { continuous constant current }{ }^{b}\end{array}$} & $207 \pm 85$ & $149 \pm 45$ & \multirow[t]{2}{*}{34} & \multirow[t]{2}{*}{$<0.001$} \\
\hline & 184 (102 to 535) & 143 (80 to 292) & & \\
\hline
\end{tabular}

Statistical analysis conducted through Wilcoxon signed-rank test. Statistically significant data are in bold

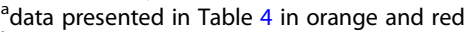

${ }^{b}$ data presented in Table 4 in blue, green, and yellow. The obtained sweat weight was associated with chloride concentration and may change the sweat test result because the amount of sweat collected could be cause in a dilution of the chloride in the own sweat. Statistically significant data are in bold. Data are presented in table as: number of individuals; mean \pm standard deviation; median (minimum to maximum) 


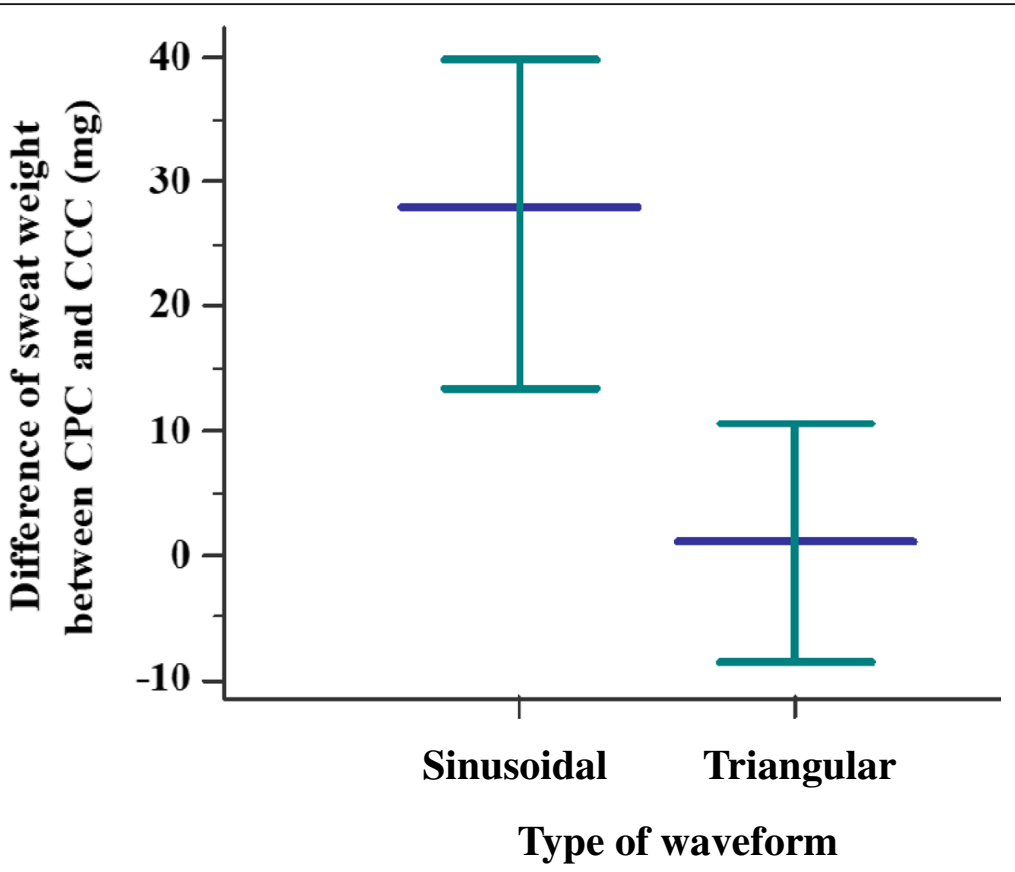

Fig. 5 Difference between sweat weight achieved from continuous pulsed current (sinusoidal versus triangular) in relation to continuous constant current showed a higher amount of sweat weight in sinusoidal pulsed current. $p$-value $=0.02$. (Sinusoidal pulsed current) $N=49 ; 34.63 \pm$ 54.02; 28 ( -58 to 231); 19.12 to 50.15; (Triangular pulsed current) $N=180 ;-0.96 \pm 85.99 ; 1$ ( -364 to 434 ); -13.6 to 11.69. Data are presented in legend as: number of individuals; mean \pm standard deviation; median (minimum to maximum); confidence interval for the mean value; and in figure as median (black line) and 95\% confidence interval (green line). Statistical analysis conducted through Mann-Whitney U test of independent samples. Alpha $=0.05$. The sweat weight is shown as milligrams

In our study, the male participants presented higher amounts of sweat with all tested currents, and lower values of electrical impedance with continuous constant current and continuous pulsed current. This fact may be associated with greater sudomotor activity in males [44, 52] and due to the skin structure. Our findings agree with the evidence found in the literature showing that males present greater sweat weight $[53,54]$.

A limiting factor for the discussion of our findings is the lack of data in the literature related to the sweat induction stage of the sweat test involving pilocarpine iontophoresis and the use of different types of currents. But, using different currents, we achieved different results in the classification of the sweat test, mainly, considering the borderline value. Also, in the present study, we included many individuals with clinical suspicion of $\mathrm{CF}$, but sometimes, without a close diagnosis (absence of two CFTR mutations and/or two sweat tests $\geq 60 \mathrm{mmol} / \mathrm{L}$ ). In this context, we found a lot of variability that could be a singular characteristic of the patient enrolled in the studied sample. And, in our work, all the currents showed a close capacity to induce the sweating.

Regardless of the current applied, the guidelines must be strictly followed when conducting the sweat test. In the method of Gibson and Cooke, some additional precautions should be taken, such as the use of gauze completely soaked with pilocarpine and of a proper size to protect the skin from the contact with the electrode, the electrode size should be standardized, since the current density should not exceed $0.16 \mathrm{~mA} / \mathrm{cm}^{2}$; the distance between the electrodes should be enough to induce the permeation of pilocarpine, and in our study, the minimum distance of two $\mathrm{cm}$ and maximum distance of five $\mathrm{cm}$ in the forearm were considered ideal for the results obtained.

Our study points to the need to properly assess the sweat weight. In our data, a large number of the evaluated individuals had a change in the outcome of the CF diagnosis, considering the increase in sweat weight collected in the sweat test. At the same time, we showed that there is a negative correlation between the chloride ion and the sweat weight, and this fact was observed in the literature [26], but other studies should be performed to close the idea behind this issue. Thus, the sweat test should be redone even when a sweat value was obtained according to the guidelines $(\geq 75 \mathrm{mg}$ ) and there was still clinical suspicion and/or positive neonatal screening. In cases where the suspicion remains after many sweat tests performed, the genetic test is necessary to confirm or not the $\mathrm{CF}$ diagnosis.

In the literature, we did not have a consensus regarding the maximum value to sweat weight where we can 

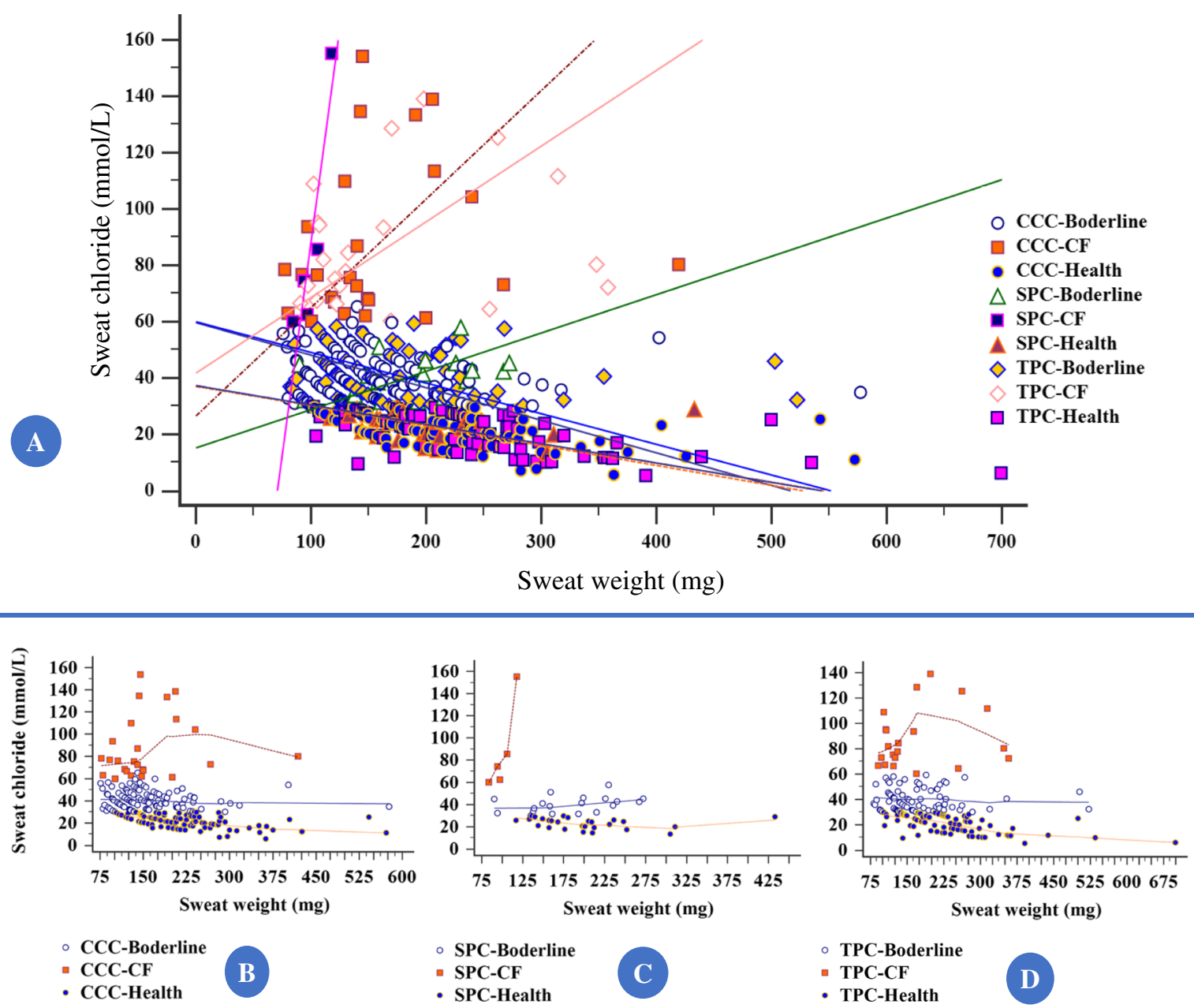

Fig. 6 Spearman's coefficient of Rank correlation (Rho) between chloride values achieved in the sweat test (mmol/L) and sweat weight (mg) showed there was a positive correlation between sweat chloride values and sweat weight. a All samples: Sample size $=460$ (sweat weight below of $75 \mathrm{mg}$ were excluded). Rho $=-0.482 ; 95 \%$ confidence interval for Rho $=-0.549$ to -0.409 . $p$-value $<0.0001$. CCC-CF $=26 / 460(5.7 \%)$; CCC-borderline = 108/460 (23.5\%); CCC-health = 97/460 (21.1\%); SPC-CF = 5/460 (1.1\%); SPC-borderline = 19/460 (4.1\%); SPC-health = 28/460 (6.1\%); TPC-CF =21/460 (4.6\%); TPC-borderline = 75/460 (16.3\%); TPC-health =81/460 (17.6\%). b CCC. Sample size $=231$. Rho $=-0.508 ; 95 \%$ confidence interval for Rho $=-0.598$ to $-0.406 . C C C-C F=26 / 231(11.26 \%)$; CCC-borderline $=108 / 231(46.75 \%)$; CCC-health $=97 / 231(41.99 \%)$. $p$-value $<0.0001$. c SPC. Sample size $=52$. Rho $=-0.361 ; 95 \%$ confidence interval for Rho $=-0.577$ to -0.098 . SPC-CF $=5 / 52(9.62 \%)$; SPC-borderline $=19 / 52(36.54 \%) ;$ SPC-health $=28 / 52$ (53.85\%). $p$-value $=0.0086 . \mathbf{d}$ TPC. Sample size $=177$. Rho $=-0.470 ; 95 \%$ confidence interval for Rho $=-0.577$ to -0.346. TPC-CF $=21 / 177(11.86 \%)$; TPC-borderline $=75 / 177(42.76 \%)$; TPC-health $=81 / 177(45.76 \%) . p$-value $<0.0001$. CCC, continuous constant current; SPC, sinusoidal pulsed current; TPC, triangular pulsed current; CF, cystic fibrosis. Chloride values (mmol/L): (i) $\mathrm{CF}-\geq 60 \mathrm{mmol} / \mathrm{L}$; (ii) borderline - between $\geq 30$ to $<60 \mathrm{mmol} / \mathrm{L}$; (iii) health - $>30 \mathrm{mmol} / \mathrm{L}$. The chloride concentration is shown as milliequivalent by liter $(\mathrm{mmol} / \mathrm{L})$. Also, the sweat weight is shown as milligrams

consider the sweat test as acceptable to CF diagnosis. Also, as previously reported by us and discussed in our present data, we found a negative correlation between sweat weight and concentration of chloride [26]. In this scenario, we believe that this fact is not important when the final sweat weight is bigger than $75 \mathrm{mg}$ until values around $100 \mathrm{mg}$, but when we have a highest sweat weight, a major influence in concentration of chloride can be achieved and representing an alteration in the classification of the patient, mainly, in cases, with normal or borderline values in sweat test.
Additional studies on sweat test should be conducted with sweat samples obtained from healthy individuals and individuals with CF using other types of waveform, different body mass indexes and ethnic groups as well as comparisons between different age groups. In addition, in our study design, we did not follow strictly the guidelines $[6,8,15,16,24]$ i.e. we used $10 \mathrm{~min}$ (versus five $\mathrm{min}$ in the guidelines) and one $\mathrm{mA}$ (versus 2.5 to four $\mathrm{mA}$ in the guidelines) to perform the sweat induction. Moreover, with the lower $\mathrm{mA}$, we needed to include a greater lapse of time to promote the sweat induction. 


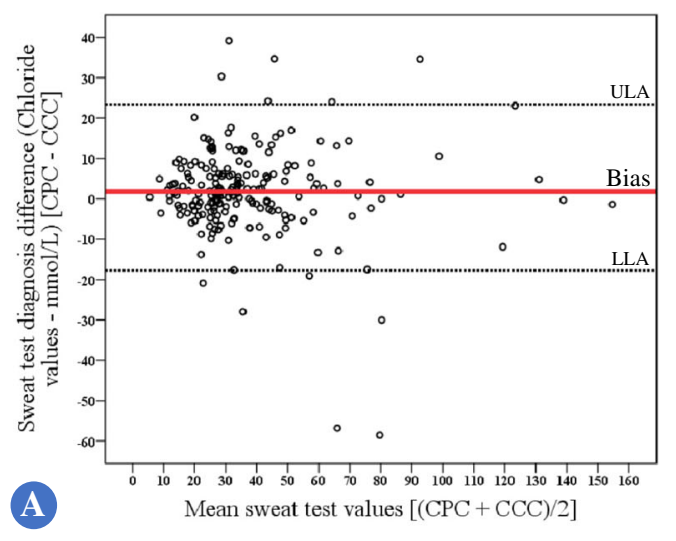

\section{Conclusion}

The evaluated currents are able to induce and produce sweat in sufficient amounts for chloride analysis. Moreover, the sinusoidal pulsed current presented lower electrical impedance when compared with the other currents and we suggest its use to induce sweat in patients with sweat problems. Also, ethnicity, gender, age and body mass index did not influence sweat induction at the sweat test, and no side effect was observed in our study.

\section{Additional files}

Additional file 1: Comparison of continuous constant current, sinusoidal pulsed current and triangular pulsed current for impedance and sweat weight. The sinusoidal pulsed current showed a minor impedance when compared with triangular pulsed current and continuous constant current. Also, the sinusoidal pulsed current was able to induce a better sweat weight than continuous constant current. (DOCX $21 \mathrm{~kb}$ )

Additional file 2: Gender comparison for the sweat test markers evaluated in our study. In all types of currents in use, females showed a low amount of sweat weight. Moreover, females have a higher impedance in use of triangular pulsed current and continuous constant current than males. (DOCX $20 \mathrm{~kb}$ )

Additional file 3: Comparison of ethnicity for the sweat test markers evaluated in our study. Caucasians have a higher body mass index than no Caucasians in the triangular pulsed current and continuous constant current groups. Also, Caucasians showed a lower Impedance than no Caucasian to sinusoidal pulsed current. (DOCX $20 \mathrm{~kb}$ )

Mean sweat test values $[(\mathrm{SPC}+\mathrm{CCC}) / 2]$

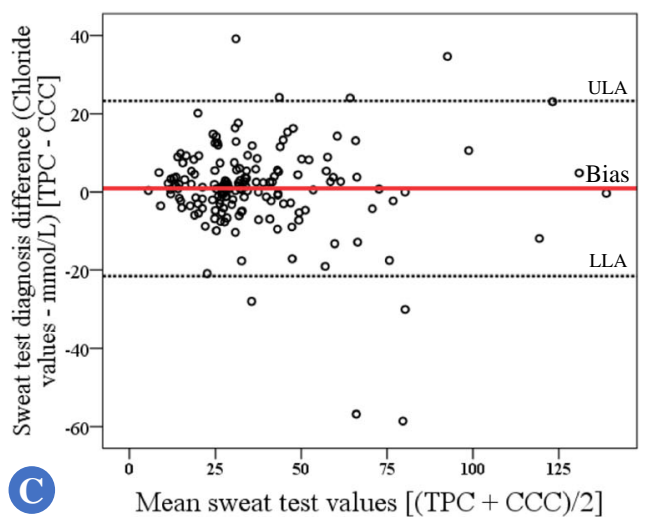

Fig. 7 Bland and Altman plot considering the agreement between the sweat chloride values achieved from continuous pulsed current and continuous constant current. a Sweat chloride values achieved from continuous pulsed current and continuous constant current $R=0.062 ; R^{2}=0.004 ; p$-value $=0.368 ;$ Bias $=1.806 ;$ ULA $=23.386 ;$ LLA $=-19.774$. $\mathbf{b}$ Sweat chloride values achieved from sinusoidal pulsed current and continuous constant current $-R=0.027 ; R^{2}=0.001$; $p$-value $=0.855 ;$ Bias $=4.891 ;$ ULA $=22.502 ;$ LLA $=-12.72$. c Sweat chloride values achieved from triangular pulsed current and continuous constant current $-R=0.074 ; R^{2}=0.005 ; p$-value $=0.349$; Bias $=0.879 ;$ ULA $=23.254 ; \mathrm{LLA}=-21.496$. ULA, upper limit of agreement; $L L A$, lower limit of agreement. The chloride concentration is shown as milliequivalent by liter (mmol/L). The statistical analysis was done with simple linear regression. Alpha $=0.05$

\section{Abbreviations}

BMI: Body mass index; CCC: Continuous constant current; CF: Cystic fibrosis; CFTR: Cystic fibrosis transmembrane regulator; CPC: Continuous pulsed current; IRMS: Effective current measure (current root mean square); OMIM: Online Mendelian Inheritance in Man; RMS: Root mean square; SPC: Sinusoidal pulsed current; ST: Sweat test; TPC: Triangular pulsed current; VRMS: Effective voltage measure (volts root mean square); Z: Composite impedance

\section{Acknowledgements}

We would like to thank Luciana Montes Rezende, Luciana Cardoso Bonadia, Stéphanie Villa-Nova Pereira, Carlos Emílio Levy, Adressa de Oliveira Peixoto, Adyléia Aparecida Contrera Dalbo Toro, Renan Marrichi Mauch, Roberto José Negrão Nogueira, Eulália Sakano, Natasha Matsunaga, Alfonso Eduardo Alvarez, Elizete Aparecida Lomazi, Paloma Lopes Francisco Parazzi, Larissa Furlan, Emília Gonçalves, Aline Cristina Gonçalves, Milena Baptistella Grotta Silva, and Aléthea Guimarães Faria, who have contributed to our studies on cystic fibrosis at our reference center. We want to thank Espaço da Escrita/Coordenadoria Geral da Universidade - Unicamp - for providing the manuscript translation; and FALM - São Paulo Research Foundation (FAPESP) for the research support and fellowships \#2011/12939-4; \#2015/12183-8, and \#2015/ 12858-5; the Fund for the Support to Education, Research, and Extension of the University of Campinas, for fellowship \#0648/2015; and JDR: FAPESP, for fellowships \#2011/18845-1 and \#2015/12183-8.

\section{Funding}

Fundação de Amparo à Pesquisa do Estado de São Paulo (FAPESP) for research support and scholarships (\#2011/12939-4, \#2011/18845-1, \#2015/ 12183-8 and \#2015/12858-5 to FALM and JDR); Fundo de Apoio à Pesquisa, ao Ensino e à Extensão da Universidade Estadual de Campinas for research support (\#0648/2015 to FALM). Conselho Nacional de Desenvolvimento Científico e Tecnológico (CNPq) for scholarship to CCSG. CNPq - Secretaria de Educação Profissional e Tecnológica/Ministério da Educação for research support (Chamada: CNPq-SETEC/MEC \#94/2013). 


\section{Availability of data and materials}

The datasets analyzed during the current study available from the corresponding author on reasonable request.

\section{Authors' contributions}

CCSG, FALM, MFS, AFR, MAGOR, VALG, ETC, JDR, and FUVJ made substantial contributions to the study conception and design, data acquisition, analysis and interpretation; as well as manuscript writing and critical revision for important intellectual content; producing the final manuscript version to be published; and agreed to be accountable for all aspects of the study, ensuring that the questions related to the accuracy or integrity of any part of the study were appropriately investigated and resolved. All authors read and approved the final manuscript.

\section{Ethics approval and consent to participate}

The project was approved by the Research Ethics Committee of the University of Campinas (\#809.090/2014). Written informed consent for participation in the study was obtained from participants or, where participants are children, from a parent or guardian.

\section{Consent for publication}

Not applicable

\section{Competing interests}

The authors declare that there is no competing interest.

\section{Publisher's Note}

Springer Nature remains neutral with regard to jurisdictional claims in published maps and institutional affiliations.

\section{Author details \\ 'Department of Pediatrics, School of Medical Sciences, University of Campinas, Cidade Universitária Zeferino Vaz, Barão Geraldo, Campinas, São Paulo 13083-887, Brazil. ${ }^{2}$ Center for Research in Pediatrics, School of Medical Sciences, University of Campinas, Cidade Universitária Zeferino Vaz, Barão Geraldo, Campinas, São Paulo 13083-887, Brazil. ${ }^{3}$ Department of Medical Genetics, School of Medical Sciences, University of Campinas, Cidade Universitária Zeferino Vaz, Barão Geraldo, Campinas, São Paulo 13083-887, Brazil. ${ }^{4}$ Gastrocentro - Endoscopy Unit, University of Campinas, Cidade Universitária Zeferino Vaz, Barão Geraldo, Campinas, São Paulo 13083-872, Brazil. ${ }^{5}$ Center for Biomedical Engineering, University of Campinas, Cidade Universitária Zeferino Vaz, Barão Geraldo, Campinas, São Paulo 13083-970, Brazil. ${ }^{6}$ Department of Biomedical Engineering, Faculty of Electrical and Computer Engineering, University of Campinas, Cidade Universitária Zeferino Vaz, Barão Geraldo, Campinas, São Paulo 13083-881, Brazil. ${ }^{7}$ Federal Institute of Education, Science and Technology of Sao Paulo, Campus Campinas, km 143.5, Campinas, São Paulo 13069-901, Brazil.}

\section{Received: 14 December 2017 Accepted: 24 July 2018}

\section{Published online: 14 September 2018}

\section{References}

1. Gibson LE, Cooke RE. A test for concentration of electrolytes in sweat in cystic fibrosis of the pancreas utilizing pilocarpine iontophoresis. Pediatrics. 1959;23:545-9

2. Collie JT, Massie RJ, Jones OA, LeGrys VA, Greaves RF. Sixty-five years since the New York heat wave: advances in sweat testing for cystic fibrosis. Pediatr Pulmonol. 2014:49:106-17. https://doi.org/10.1002/ppul.22945.

3. Marson FAL, Bertuzzo CS, Ribeiro JD. Personalized drug therapy in cystic fibrosis: from fiction to reality. Curr Drug Targets. 2015;16:1007. https://doi. org/10.2174/1389450115666141128121118.

4. Marson FAL, Bertuzzo CS, Ribeiro JD. Personalized or precision medicine? The example of cystic fibrosis. Front Pharmacol. 2017;8:390. https://doi.org/ 10.3389/fphar.2017.00390.

5. Marson FAL. Disease-modifying genetic factors in cystic fibrosis. Curr Opin Pulm Med. 2018;24(3):296-308. https://doi.org/10.1097/MCP. 0000000000000479.

6. LeGrys VA, Yankaskas JR, Quittell LM, Marshall BC, Mogayzel PJ Jr. Diagnostic sweat testing: the cystic fibrosis foundation guidelines. J Pediatr. 2007;151: 85-9. https://doi.org/10.1016/j.jpeds.2007.03.002.
7. Castellani C, Southern KW, Brownlee K, Dankert RJ, Duff A, Farrell M, et al. European best practice guidelines for cystic fibrosis neonatal screening. J Cyst Fibros. 2009;8(Suppl 3):153-73. https://doi.org/10.1016/j.jff.2009.01.004.

8. Farrell PM, White TB, Ren CL, Hempstead SE, Accurso F, Derichs N, et al. Diagnosis of cystic fibrosis: consensus guidelines from the cystic fibrosis foundation. J Pediatr. 2017;181:S4-S15. https://doi.org/10.1016/j.jpeds.2016 09.064.

9. Kirk JM. Inconsistencies in sweat testing in UK laboratories. Arch Dis Child. 2000;82:425-7. https://doi.org/10.1136/adc.82.5.425.

10. Beauchamp M, Grey V, Lands LC. Sweat collection for testing in Canadian cystic fibrosis centers: is it optimal? Clin Biochem. 2005;38:934-7. https://doi. org/10.1016/j.clinbiochem.2005.05.007.

11. Mackay R, George P, Kirk J. Sweat testing for cystic fibrosis: a review of New Zealand laboratories. J Paediatr Child Health. 2006;42:160-4. https://doi.org/ 10.1111/j.1440-1754.2006.00822.x.

12. Barben J, Casaulta C, Spinas R, Schöni MH. Sweat testing practice in Swiss hospitals. Swiss Med Wkly. 2007;137:192-8. https://doi.org/10.4414/ smw.2007.11719.

13. Cirilli N, Podan R, Raia V. Audit of sweat testing: a first report from Italian cystic fibrosis centres. J Cyst Fibros. 2008;7(Suppl 5):415-22. https://doi.org/ 10.1016/j.jcf.2008.03.005.

14. Castellani C, Conway S, Smyth AR, Stern M, Elborn JS. Standards of care for cystic fibrosis ten years later. J Cyst Fibros. 2014;13(Suppl 1):S1-2. https://doi. org/10.1016/j.jcf.2014.03.008.

15. Heap S, Griffiths P, Elborn S, Harris B, Wayte B, Wallis CE, Weller P, Sheldrake A, Nixon W, Lacy D. Guidelines for the performance of the sweat test for the investigation of cystic fibrosis in the UK v. 2. An evidence-based guideline; 2014. p. 1-151.

16. Massie J, Greaves R, Metz M, Wiley V, Graham P, Shepherd S, Mackay R. Australasian guideline ( $2^{\text {nd }}$ edition): an annex to the CLSI and UK guidelines for the performance of the sweat test for the diagnosis of cystic fibrosis. Clin Biochem Rev. 2017;38(Suppl 3):115-30.

17. Salvatore M, Floridia G, Amato A, Censi F, Carta C, de Stefano MC, et al. The Italian pilot external quality assessment program for cystic fibrosis sweat test. Clin Biochem. 2016;49(Suppl 7-8):601-5. https://doi.org/10.1016/j. clinbiochem.2015.12.014.

18. Webster HL. A clinical appraisal of cystic fibrosis sweat-testing guidelines. Am Clin Lab. 2001;20:39-42.

19. Hammond KB, Nelson L, Gibson LE. Clinical evaluation of the macroduct sweat collection system and conductivity analyzer in the diagnosis of cystic fibrosis. J Pediatr. 1994;124:255-60. https://doi.org/10.1016/S00223476(94)70314-0.

20. Servidoni MF, Gomez CCS, Marson FAL, Toro AADC, Ribeiro MAGO, Ribeiro JD, et al. Sweat test and cystic fibrosis: overview of test performance at public and private centers in the state of São Paulo, Brazil. J Bras Pneumol. 2017;43(Suppl 2):121-8. https://doi.org/10.1590/ S1806-37562016000000076.

21. Bagniefski T, Burnette RR. A comparison of pulsed and continuous current iontophoresis. J Control Release. 1990;11:113-22. https://doi.org/10.1016/ 0168-3659(90)90125-D.

22. Knoblauch P, Moll F. In vitro pulsatile and continuous transdermal delivery of buserelin by iontophoresis. J Control Release. 1993;26(Suppl 3):203-12. https://doi.org/10.1016/0168-3659(93)90187-A.

23. Gomez CC, Servidoni MF, Marson FAL, Canavezi PJ, Vinagre AM, Costa ET, et al. Pulsed direct and constant direct currents in the pilocarpine iontophoresis sweat chloride test. BMC Pulm Med. 2014;14:198. https://doi. org/10.1186/1471-2466-14-198.

24. The Clinical and Laboratory Standards Institute (CLSI). Sweat testing: sample collection and quantitative chloride analysis; approved guideline - third edition. C34-A3:2009. Wayne: CLSl; 2009.

25. Faria AG, Marson FAL, Gomez CC, Ribeiro MAGO, Morais L, Servidoni M, et al. Quality of sweat test (ST) based on the proportion of sweat sodium (Na) and sweat chloride (Cl) as diagnostic parameter of cystic fibrosis: are we on the right way? Diagn Pathol. 2016;11(Suppl 1):103. https://doi.org/10.1186/ s13000-016-0555-6.

26. Faria AG, Marson FAL, Gomez CCS, Servidoni MF, Ribeiro AF, Ribeiro JD. Thirty years of sweat chloride testing at one referral center. Front Pediatr. 2017;5:222. https://doi.org/10.3389/fped.2017.00222.

27. Faria AG, Marson FAL, Ribeiro AF, Ribeiro JD. The correlation between age and sweat chloride levels in sweat tests. Rev Port Pneumol (2006). 2017;23(Suppl 4):227-30. https://doi.org/10.1016/j.rppnen.2016.11.001. 
28. Wallis C. Diagnosing cystic fibrosis: blood, sweat, and tears. Arch Dis Child. 1997;76:85-8. https://doi.org/10.1136/adc.76.2.85.

29. Taylor CJ, Hardcastle J, Southern KW. Physiological measurements confirming the diagnosis of cystic fibrosis: the sweat test and measurements of transepithelial potential difference. Paediatr Respir Rev. 2009;10:220-6. https://doi.org/10.1016/.jprrv.2009.05.002.

30. Beauchamp M, Lands LC. Sweat-testing: a review of current technical requirements. Pediatr Pulmonol. 2005;39:507-11. https://doi.org/10. 1002/ppul.20226.

31. LeGrys VA. Sweat analysis proficiency testing for cystic fibrosis. Pediatr Pulmonol. 2000;30(Suppl 6):476-80. https://doi.org/10.1002/10990496(200012)30:6<476::AID-PPUL7>3.0.CO;2-O.

32. Jakobsson BM, Salomonnson S, Hjelte L. Sweat test in Sweden 2002 - a cross sectional study. J Cyst Fibros. 2004;(Suppl 1):E441.

33. Naehrlich L. Sweat testing practices in German cystic fibrosis centers. Klim Padiatr. 2007;219(Suppl 2):70-3.

34. Umino M. Research of transcutaneous and transmucosal drug delivery and it's perspective. J Stomatol Soc Jpn. 2009;76:1-7.

35. Ledger PW. Skin biological issues in electrically enhanced transdermal delivery. Adv Drug Deliv Ver. 1992;9:289-307. https://doi.org/10.1016/ 0169-409X(92)90027-N.

36. Chien YW, Lelawongs $P$, Siddiqui $O$, Sun $Y$, Shi WM. Facilitated transdermal delivery of therapeutic peptides and proteins by iontophoretic delivery devices. J Control Release. 1990;13:263-78. https://doi.org/10.1016/0168-3659(90)90017-N.

37. Panzade P, Heda A, Puranik P, Patni M, Mogal V. Enhanced transdermal delivery of granisetron by using iontophoresis. Iran J Pharm Res. 2012; 11(Suppl 2):503-12. https://doi.org/10.15272/jmpi.v1i01.6.

38. Banga AK, Chien YW. lontophoretic delivery of drugs: fundamentals, developments and biomedical application. J Control Release. 1988;7(Suppl 1): 1-24. https://doi.org/10.1016/0168-3659(88)90075-2.

39. Chen LLH, Chien YW. Transdermal iontophoretic permeation of luteinizing hormone releasing hormone: characterization of electric parameters. J Control Release. 1996;40:187-98. https://doi.org/10.1016/ 0168-3659(95)00181-6.

40. Chien YW, Siddiqui O, Shi WM, Lelawongs P, Liu JC. Direct current iontophoretic transdermal delivery of peptide and protein drugs. J Pharm Sci. 1989;78:376-83. https://doi.org/10.1002/jps.2600780507.

41. Hirvonen J, Hueber F, Guy RH. Current profile regulates iontophoretic delivery of amino acids across the skin. J Control Release. 1995;37:239-49. https://doi.org/10.1016/0168-3659(95)00081-X.

42. Kanebako M, Inagi T, Takayama K. Transdermal delivery of iondomethacin by iontophoresis. Biol Pharm Bull. 2002;25:779-82. https://doi.org/10.1248/bpb.25.779.

43. Elias PM. Epidermal barrier function: intercellular lamellar lipid structures, origin, composition and metabolism. J Control Release. 1991;15(Suppl 3): 199-208. https://doi.org/10.1016/0168-3659(91)90111-P.

44. Lee JB, Kim JH, Murota H. Perspiration functions in different ethnic, age, and sex populations: modification of sudomotor function. Curr Probl Dermatol. 2016;51:109-19. https://doi.org/10.1159/000447370.

45. Kyle UG, Bosaeu I, De Lorenzo AD, Deurenberg P, Elia M, Gómez JM, et al. Bioelectrical impedance analysis-part I: review of principles and methods. Clin Nutr. 2004;23(Suppl 5):1226-43. https://doi.org/10. 1016/j.cInu.2004.06.004

46. Nakakura M, Kato Y, Hayakawa E, Kuroda T. Effect of pulse on iontophoretic delivery of desmopressin acetate in rats. Biol Pharm Bull. 1996;19:738-40. https://doi.org/10.1248/bpb.19.738.

47. Barry BW. Drug delivery routes in skin: a novel approach. Adv Drug Deliv Rev. 2002;4:S31-40. https://doi.org/10.1016/S0169409X(02)00113-8.

48. Pikal MJ. The role of electroosmotic flow in transdermal iontophoresis. Adv Drug Deliv Rev. 1992;9:201-37. https://doi.org/10. 1016/50169-409X(00)00138-1.

49. Sagi-Dolev AM, Prutchi D, Nathan RH. Three-dimensional current density distribution under surface stimulation electrodes. Med Biol Eng Comput. 1995;33(Suppl 3):403-8.

50. Chizmadzhev YA, Indenbom AV, Kuzmin PI, Galichenko SV, Weaver JC, Potts RO. Electrical properties of skin at moderate voltages: contribution of appendageal macropores. Biophys J. 1998;74(Suppl 2):843-56.
51. Ya-Xian Z, Suetake T, Tagami H. Number of cell layers of the stratum corneum in normal skin - relationship to the anatomical location on the body, age, sex and physical parameters. Arch Dermatol Res. 1999; 291(Suppl 10):555-9.

52. Quinton PM. Defective epithelial ion transport in cystic fibrosis. Clin Chem. 1989:35(Suppl 5):726-30.

53. Baker LB, Barnes KA, Anderson ML, Passe DH, Stofan JR. Normative data for regional sweat sodium concentration and whole-body sweating rate in athletes. J Sports Sci. 2016;34(Suppl 4):358-68. https://doi.org/10.1080/ 02640414.2015.1055291.

54. Meyer F, Bar-Or O, MacDougall D, Heigenhauser GJ. Sweat electrolyte loss during exercise in the heat: effects of gender and maturation. Med Sci Sports Exerc. 1992;24:776-81. https://doi.org/10.1249/ 00005768-199207000-00007.

\section{Ready to submit your research? Choose BMC and benefit from:}

- fast, convenient online submission

- thorough peer review by experienced researchers in your field

- rapid publication on acceptance

- support for research data, including large and complex data types

- gold Open Access which fosters wider collaboration and increased citations

- maximum visibility for your research: over $100 \mathrm{M}$ website views per year

At BMC, research is always in progress.

Learn more biomedcentral.com/submissions 